\title{
Cellular Telephone Number
}

National Cancer Institute

\section{Source}

National Cancer Institute. Cellular Telephone Number. NCI Thesaurus. Code C81240.

The sequence of numbers or characters, that when dialed, connects to a particular cellular telephone. 